\title{
Association between Changes in Chronotype during Clerkship and Defense Style among Medical Students
}

\author{
So-Jin Lee1, Chul-Soo Park1, Bong-Jo Kim¹, Cheol-Soon Lee², Boseok Cha', \\ Jin-Seong Lee ${ }^{3}$, Dongyun Lee ${ }^{2}$, Jiyeong Seo², and Jae-Won Choi ${ }^{1}$ \\ 'Department of Psychiatry, Gyeongsang National University School of Medicine and Gyeongsang National University Hospital, Jinju, Korea \\ 2Department of Psychiatry, Gyeongsang National University School of Medicine and Gyeongsang National University Changwon Hospital, \\ Changwon, Korea \\ ${ }^{3}$ Kosleep Sleep Clinic, Seoul, Korea
}

\begin{abstract}
Objective: We explored the association of the changes in and mechanisms underlying the defense styles of medical students with their chronotype during clinical clerkship. Methods: In total, 187 medical students (94 men) aged 24-38 years completed the Morningness-Eveningness Questionnaire and the Korean version of the Defense Style Questionnaire at the start and end of their clerkship. The Hospital Anxiety and Depression Scale, Insomnia Severity Scale, and Sleep Habit-related Questionnaire were administered at the end of the clerkship. Results: The Wilcoxon signed-rank test showed a significant change toward morningness during the clinical clerkship $(W=9,085.5, p=0.018, r=0.18)$. A multiple linear regression analysis showed that an increase in morningness $(\beta=-0.254, p=0.001)$ and a decrease in splitting $(\beta=0.397, p<0.001)$ predicted less use of an immature defense style after the clerkship when controlling for age, sex, depression, and sleep quality. Conclusion: Increased morningness and a gradual reduction in splitting during clerkship may help reduce immaturity in medical students.
\end{abstract}

Key Words: Immature defense style; Medical students; Chronotype; Splitting

Received: December 5, 2018 Revised: January 21, 2019 Accepted: January 21, 2019

Corresponding author: Chul-Soo Park, MD, PhD, Department of Psychiatry, Gyeongsang National University School of Medicine and Gyeongsang National University Hospital, 79 Gangnam-ro, Jinju 52727, Korea.

Tel: 82-55-750-8086, Fax: 82-55-759-0003, E-mail: cspark8083@gmail.com

(a) This is an Open Access article distributed under the terms of the Creative Commons Attribution Non-Commercial License (https://creativecommons.org/licenses/bync/4.0) which permits unrestricted non-commercial use, distribution, and reproduction in any medium, provided the original work is properly cited.

\section{INTRODUCTION}

Poor sleep quality, sleep deprivation, and excessive daytime sleepiness are common in medical students, especially during clinical clerkship [1-3]. Sleep disturbances may partly reflect the fact that the normal circadian rhythm clashes with early clinical schedules. Circadian preference is associated with specific personality patterns in young adults [4-7]. The morning-type preference has been reported to be associated with higher conscientiousness and agreeableness and lower openness to experience, extraversion, and neuroticism [6]. In terms of the latter, morningness tends to be associated with low-level neuroticism $[4,8]$, although some studies have reported a negative or no relationship between morningness and neuroticism $[7,9]$. Eveningness is associated with depression [10-12], eating disorders [13], anxiety
[14], addiction [15-17], and personality disorders [4,7,18].

Morningness has been found protect against sleep-related psychological problems in childhood and adolescence [19]. It has been suggested that the chronotype of young adults be considered in developing programs to prevent mental health problems [4]. Thus, it is important to evaluate the chronotype of medical students to determine whether it is related in important ways to personality. As it has been established that a shift toward morningness occurs after early adulthood [20,21], it is also crucial to determine whether significant changes in circadian preference are likely to occur during clinical clerkship. Changes in chronotype may be related to certain defenses, and to changes in defense mechanisms and defense styles during clerkship.

Therefore, we explored the defense styles, defense mechanisms, and chronotypes of medical students before and after clinical 
clerkship. We expected that certain defenses and/or changes in defenses would be associated with chronotype and/or with changes in chronotype. We hypothesized that meaningful changes in circadian preference would occur through clinical clerkship, and these changes may be associated with the use of certain defenses and/or changes in defenses.

\section{MATERIALS AND METHODS}

\section{Participants}

This study is part of a larger project, 'A Study on the PhysicianPatient Interactions (PPIs) of Medical Students [22], which followed three successive cohorts from the start of their second year in 2012 through the end of their fourth year in 2016. The study was performed at the medical school of Gyeongsang National University (GNU) in Jinju City, Republic of Korea. All those who agreed to participate provided written informed consent and completed questionnaires during the first 2 weeks of August in their second year in 2012, 2013, and 2014. After clinical rotations in clinical departments, the same students completed the questionnaires in September 2014, 2015, and 2016. Students who withdrew temporarily or permanently were excluded. Student identities were managed separately, and the questionnaires were anonymized. Any student exhibiting a high-risk mental health issue was so informed, and psychiatric evaluation was recommended based on the cutoff of the Hospital Anxiety and Depression Scale. The data on 148 year- 2 students in 2012 and 2013 were analyzed as a cross-sectional study, which has been published [5]. We recruited 216 year-2 students, of whom 187 (94 males and 93 females) aged 24-38 years (mean, 28.9 \pm 2.8 years) completed questionnaires at year 4 . Students were divided into three groups by year; group I included participants who were in year 2 in 2012 and year 4 in 2014; group II included students who were in year 2 in 2013 and year 4 in 2015; group III included subjects who were in year 2 in 2014 and year 4 in 2016. The institutional review board of GNU approved this study (IRB file number: GIRB-A14-Y-0051).

\section{Assessment}

The questionnaires included the Korean versions of the Defense Style Questionnaire (K-DSQ) [23] and the MorningnessEveningness Questionnaire (MEQ) [24]. The Hospital Anxiety and Depression Scale (HADS) [25], the Korean version of the Insomnia Severity Index (ISI-K) [26], and a sleep-habit questionnaire evaluating weekend oversleeping, exposure to sunlight from 10:00 to 15:00, rising time difference between weekdays and weekends, and total sleep time during weekdays and weekends were administered to all fourth-year students.

The K-DSQ is a psychometric instrument comprising 65 questions that evaluate individual thoughts and behaviors. Sixteen defense mechanisms, which are grouped into four defense styles, are explored. The adaptive defense style consists of humor, sublimation, omnipotence, and denial. The immature defense style consists of consumption, passive aggression, fantasy, splitting, projec- tion, and acting out. The self-repressive defense style consists of suppression, reaction formation, undoing, and withdrawal. The conflict-avoidant style includes resignation and isolation. Although the wording of K-DSQ items indicates that defenses are traits, defense mechanisms and styles can also be viewed as outcomes [27]. We examined differences between year- 2 and year- 4 participants with regard to defense styles and use of 16 defense mechanisms, to identify personality changes during clerkship.

The HADS, used to measure depression and anxiety in fourthyear students, has been employed both for in-hospital screening and to evaluate general populations, such as university students $[28,29]$. The scale consists of 14 items divided equally into anxiety (HADS-A) and depression (HADS-D) subscales, and each item is graded on a scale from 0 to 3 [25]. The Korean version of the HADS is valid and reliable, and the HADS-A and HADS-D cutoffs for anxiety and depression diagnosis, respectively, are both 8 [30]. The internal reliability in the present study was adequate (Cronbach's a for HADS-A=0.83; for HADS-D=0.74).

The MEQ was used to estimate morningness/eveningness and changes therein after the clinical years. This self-report questionnaire consists of 19 items, and total scores ranged from 16 to 86; higher scores indicate greater morningness. The Korean version of the MEQ is reliable and valid [31,32]. The internal reliability in the present study was adequate (Cronbach's $\alpha$ for year- 2 students= 0.70 ; for year- 4 students $=0.81$ ).

The ISI-K was used to evaluate the sleep quality of year- 4 students. This self-report instrument is reliable and valid when used to assess insomnia in Koreans [26]. The ISI-K consists of seven items, each rated on a five-point Likert scale; the total score ranges from 0 to 28 . Higher scores reflect more severe insomnia; the optimal cutoff was 15.5 [26]. The internal reliability in the present study was adequate (Cronbach's $\alpha=0.81$ ). Other sleep-habit-related variables were also assessed. To measure mean sleep durations on weekdays and weekends, we asked, "How many hours do you sleep on average on weekdays (this might be different from the duration of lying down on the bed)?" and "How many hours do you sleep on average on weekends?" To explore rise time misalignment between weekdays and weekends, we asked, "On average, what time do you get out of bed on weekdays?" and "On average, what time do you get out of bed on weekends?" We then calculated the absolute difference (the misalignment) [33]. We also asked: "On average, how long do you spend outside (e.g., walking, taking exercise, or just sitting on a bench) between 10:00 and 15:00 on weekdays?" and "On average, how long do you spend outside (e.g., walking, taking exercise, or just sitting on a bench) between 10:00 and 15:00 on weekends?" Differences in sleep duration between weekdays and weekends were calculated to estimate weekend oversleep [33].

\section{Statistical Analysis}

Pearson's correlations were calculated between parametric variables, and Spearman's correlations between non-parametric variables. Differences in parametric variables by year were examined 
using analysis of variance; post hoc analysis featured Fisher's least significant difference test. Differences in non-parametric variables by year were evaluated using the Kruskal-Wallis test; we also performed pairwise comparisons. Defense styles and mechanisms and morningness/eveningness at years 2 and 4 were compared using the paired $\mathrm{t}$-test for parametric data and the related-samples Wilcoxon signed-rank test for non-parametric data. We included variables with significant correlation coefficient as the continuous variables in multiple regression analyses $(\mathrm{p}<0.05)$.

We performed multiple linear regression to identify personality-related predictors of changes in morningness/eveningness from years 2 to 4 after controlling for age and sex. Another multiple linear regression was performed to identify personality-related predictors of changes in morningness/eveningness from years 2 to 4 after controlling for age, sex, depression, and sleep quality at year 4 . We performed multiple regression analysis to identify year- 4 personality-related predictors of year- 4 circadian preference after controlling for age, sex, year, depression, and sleep quality at year 4, as well as other sleep-related variables including rising time misalignment between weekdays and weekends, weekend oversleep, and the mean amount of sunlight exposure between 10:00 and 15:00. All analyses were performed using SPSS for Macintosh software (ver. 23.0; IBM Corp., Armonk, NY, USA), and a two-tailed $\mathrm{p}$-value $<0.05$ was considered to indicate statistical significance.

\section{RESULTS}

The MEQ score increased (i.e., a change toward morningness) from year 2 to 4 ( $\mathrm{W}=9,085.5, \mathrm{p}=0.018, \mathrm{r}=0.18$ ). The MEQ scores at year 2 differed among year-groups I-III; post hoc analysis showed that group III had a higher mean MEQ score than did groups I and II (Table 1). The MEQ scores at year 4 did not differ significantly among the year-groups, except that group II exhibited a significantly higher MEQ score than did group I (Table 1). Changes toward morningness from years 2 to 4 were significant- ly correlated with splitting at year $2(\rho=-0.29, \mathrm{p}<0.001, \mathrm{~N}=176)$, changes in splitting from year 2 to $4(\rho=0.19, p=0.010, N=174)$, consumption at year $4(\rho=-0.17, p=0.026, N=177)$, and use of the immature defense style at year $4(\rho=-0.15, p=0.043, N=176)$. Multiple linear regression analysis showed that less splitting at year 2 predicted a greater change toward morningness from year 2 to 4 after controlling for age and sex (Table 2). Another multiple linear regression analysis showed that female sex, less splitting at year 2, and lower use of the immature defense style at year 4 were significantly associated with more change in the direction of morningness over the 2 years of clerkship after controlling for age, depression, and sleep quality at year 4 (Table 3 ). In terms of individual defenses, less splitting at year 2 and less consumption at year 4 were significantly associated with a greater increase in morningness from year 2 to 4 after controlling for age, sex, depression, and sleep quality at year 4 and with changes in splitting from year 2 to 4 (Table 4). We then explored whether more change in the direction of morningness truly predicted less use of consumption and of the immature defense style at year 4 (Tables 5 and 6). Multiple linear regression analysis showed that splitting at year 2 and differences in morningness significantly predicted consumption at year 4 after controlling for age, sex, depression, and year-4 sleep quality (Table 5). Another multiple linear regression analysis revealed that increases in morningness and decreases in splitting

Table 2. Multiple linear regression assessing baseline defense mechanism as a predictor of differences in morningness/eveningness during clerkship

\begin{tabular}{lcccc} 
& $\mathrm{B}$ & $\begin{array}{c}\text { Standard } \\
\text { error }\end{array}$ & $\beta$ & $\mathrm{p}$-value \\
Intercept & 0.019 & 7.562 & & 0.998 \\
Age (years) & 0.311 & 0.241 & 0.096 & 0.199 \\
Sex (female=0, male=1) & -2.159 & 1.324 & -0.120 & 0.105 \\
Splitting (year 2) & -2.000 & 0.723 & -0.205 & 0.006 \\
\hline
\end{tabular}

Dependent variable: MEQ difference (between years 2 and 4 ). $\mathrm{R}^{2}=0.07$, adjusted $\mathrm{R}^{2}=0.05, \mathrm{~F}=4.3(\mathrm{p}<0.05), \mathrm{N}=175$. MEQ: Morningness-Eveningness Questionnaire

Table 1. Students' baseline demographic data and MEQ, HADS, and ISI scores for the three year-groups (I, II, and III)

\begin{tabular}{|c|c|c|c|c|c|c|}
\hline & $\begin{array}{l}\text { Total subjects } \\
\quad(\mathrm{n}=187)\end{array}$ & $\begin{array}{l}2012-2014(\mathrm{I}) \\
\text { group }(\mathrm{n}=59)\end{array}$ & $\begin{array}{l}2013-2015(\mathrm{II}) \\
\text { group }(\mathrm{n}=71)\end{array}$ & $\begin{array}{l}2014-2016(\mathrm{III}) \\
\text { group }(\mathrm{n}=57)\end{array}$ & $\begin{array}{c}\mathrm{F}^{*}(\mathrm{p} \text {-value }) \text { or } \\
\mathrm{H}^{\dagger}(\mathrm{p} \text {-value })\end{array}$ & $\begin{array}{l}\text { Post hoc or pairwise } \\
\text { comparison }\end{array}$ \\
\hline Age (year 4) (years) & $28.9 \pm 2.8$ & $28.4 \pm 2.7$ & $28.9 \pm 2.8$ & $29.4 \pm 2.8$ & $4.0^{\dagger}(\mathrm{p}=0.14)$ & \\
\hline Male (\%) & $94(50.3)$ & $30(50.8)$ & $29(40.8)$ & $36(61.4)$ & $\chi^{2}=5.36(\mathrm{p}=0.07)^{\ddagger}$ & \\
\hline $\begin{array}{l}\text { MEQ score (year 2) } \\
(\mathrm{n}=183)\end{array}$ & $44.4 \pm 8.9$ & $41.5 \pm 8.2(\mathrm{n}=57)$ & $45.4 \pm 8.7(n=70)$ & $46.2 \pm 9.2(\mathrm{n}=56)$ & $4.8^{*}(\mathrm{p}=0.009)$ & I $<$ III, II $<$ III \\
\hline $\begin{array}{l}\text { MEQ score (year } 4) \\
(n=182)\end{array}$ & $46.0 \pm 8.9$ & $43.6 \pm 8.6(n=57)$ & $47.4 \pm 8.9(n=69)$ & $46.6 \pm 8.8(n=56)$ & $3.1^{*}(\mathrm{p}=0.05)$ & $\mathrm{I}<\mathrm{II}$ \\
\hline $\begin{array}{l}\text { HADS-D (year } 4) \\
(n=186)\end{array}$ & $5.8 \pm 3.3$ & $5.7 \pm 2.9(\mathrm{n}=58)$ & $6.7 \pm 3.8(\mathrm{n}=71)$ & $4.9 \pm 2.7(n=57)$ & $4.9^{*}(\mathrm{p}=0.008)$ & $\mathrm{II}>\mathrm{III}$ \\
\hline $\begin{array}{l}\text { HADS-A (year 4) } \\
(\mathrm{n}=186)\end{array}$ & $6.0 \pm 3.0$ & $5.2 \pm 2.7(\mathrm{n}=59)$ & $6.2 \pm 3.4(\mathrm{n}=71)$ & $6.5 \pm 2.7(n=57)$ & $5.6^{\dagger}(\mathrm{p}=0.06)$ & \\
\hline ISI (year 4) $(\mathrm{n}=183)$ & $6.2 \pm 4.3$ & $5.7 \pm 4.0(\mathrm{n}=56)$ & $6.4 \pm 4.5(\mathrm{n}=71)$ & $6.3 \pm 4.4(\mathrm{n}=56)$ & $0.7^{+}(\mathrm{p}=0.72)$ & \\
\hline
\end{tabular}

Data are expressed as $\mathrm{n}(\%)$ or as means \pm standard deviation. ${ }^{*}$ Analysis of variance, ${ }^{\dagger}$ Kruskal-Wallis test, ${ }^{\ddagger}$ chi-squared test. MEQ: MorningnessEveningness Questionnaire; ISI: Insomnia Severity Index; HADS-D: Hospital Anxiety and Depression Scale-Depression; HADS-A: Hospital Anxiety and Depression Scale-Anxiety 
from year 2 to 4 significantly predicted less use of the immature defense style at year 4 after controlling for age, sex, depression, and sleep quality at year 4 (Table 6).

Circadian preference at year 4 was significantly correlated with year- 4 use of the immature defense style $(\rho=-0.22, p=0.003, N=$ 180 ), sublimation ( $\rho=0.18, p=0.015, N=181)$, consumption $(\rho=-0.19$, $\mathrm{p}=0.011, \mathrm{~N}=181)$, and passive aggression $(\mathrm{r}=-0.23, \mathrm{p}=0.002, \mathrm{~N}=181)$ and with year- 4 sleep quality (ISI scores; $\rho=-0.17, p=0.023, \mathrm{~N}=$ $178)$, rising time misalignment between weekdays and weekends ( $\rho=-0.32, \mathrm{p}<0.001, \mathrm{~N}=179)$, weekend oversleep $(\rho=-0.26, \mathrm{p}<0.001$, $\mathrm{N}=181$ ), and mean sunlight exposure from 10:00 to 15:00 ( $\rho=0.18$,

Table 3. Multiple linear regression assessing baseline defense mechanisms and defense style after clerkship as predictors of changes in morningness/eveningness from year 2 to 4

\begin{tabular}{lrrrr} 
& $\mathrm{B}$ & $\begin{array}{c}\text { Standard } \\
\text { error }\end{array}$ & $\beta$ & $\mathrm{p}$-value \\
Intercept & 8.945 & 8.093 & & 0.271 \\
Age (years) & 0.331 & 0.231 & 0.106 & 0.154 \\
Sex (female=0, male=1) & -2.834 & 1.287 & -0.162 & 0.029 \\
HADS-D (year 4) & 0.035 & 0.213 & 0.013 & 0.869 \\
ISI (year 4) & -0.100 & 0.166 & -0.048 & 0.549 \\
Splitting (year 2) & -2.409 & 0.721 & -0.247 & 0.001 \\
Immature defense style (year 4) & -2.345 & 1.125 & -0.157 & 0.039 \\
\hline
\end{tabular}

Dependent variable: MEQ difference (between years 2 and 4$) . \mathrm{R}^{2}=0.14$, adjusted $\mathrm{R}^{2}=0.11, \mathrm{~F}=4.5$ ( $\left.\mathrm{p}<0.001\right), \mathrm{N}=169$. MEQ: Morningness-Eveningness Questionnaire, HADS-D: Hospital Anxiety and Depression Scale-Depression, ISI: Insomnia Severity Index $\mathrm{p}=0.032, \mathrm{~N}=143$ ). Multiple linear regression showed that female sex, better sleep quality, less use of passive aggression, and greater sublimation at year 4 were significantly associated with morningness after controlling for year-group, depression, and sleep-habit related variables; the model explained $29 \%$ of the variance in MEQ scores at year 4 (Table 7).

\section{DISCUSSION}

We found a significant change in favor of morningness by year 4. The within-year-group differences were less marked at year 4 than at year 2 . The change toward morningness was significantly related to year-2 splitting after controlling for age and sex. Thus, students who exhibited less splitting at baseline moved toward morningness when experiencing stressful, difficult, but exciting clinical situations. The clinical educational schedule can act as a zeitgeber as clinical work commences 30-60 min earlier than preclinical lectures [34]. Eveningness is usually related to difficulties in managing environmental and social demands, and these problems may worsen when educational schedules become stressful $[35,36]$. Moreover, eveningness is reportedly associated with poor self-control [37] and impulsivity [38], reflecting brain serotonergic functioning $[39,40]$. Students who engage in splitting may exhibit less self-control, including poor self-regulation of bedtime; thus, habits compatible with clerkship schedules may be difficult to sustain, limiting any move toward morningness, or even creating a move toward eveningness, during the period of clinical train-

Table 4. Multiple linear regression assessing baseline defense mechanisms, changes in defense mechanisms, and defense mechanisms after clerkship as predictors of changes in morningness/eveningness from year 2 to 4

\begin{tabular}{lcccr} 
& B & Standard error & $\beta$ & \\
Intercept & 11.731 & 7.997 & 0.144 \\
Age (years) & 0.296 & 0.225 & 0.094 & 0.191 \\
Sex (female=0, male=1) & -2.439 & 1.258 & -0.140 \\
HADS-D (year 4) & -0.072 & 0.207 & -0.027 & 0.054 \\
ISI (year 4) & -0.123 & 0.161 & -0.059 & 0.727 \\
Splitting (year 2) & -2.389 & 0.929 & -0.244 & 0.445 \\
Splitting difference (between years 2 and 4) & 0.626 & 0.791 & 0.075 & 0.011 \\
Consumption (year 4) & -2.442 & 0.654 & -0.269 & $<0.001$ \\
\hline
\end{tabular}

Dependent variable: MEQ difference (between years 2 and 4 ). $\mathrm{R}^{2}=0.19$, adjusted $\mathrm{R}^{2}=0.16, \mathrm{~F}=5.5$ ( $\left.\mathrm{p}<0.001\right)$, $\mathrm{N}=168$. MEQ: Morningness-Eveningness Questionnaire, HADS-D: Hospital Anxiety and Depression Scale-Depression, ISI: Insomnia Severity Scale

Table 5. Multiple linear regression assessing baseline defense mechanism and differences in chronotype during clerkship as predictors of consumption at year 4

\begin{tabular}{|c|c|c|c|c|}
\hline & B & Standard error & $\beta$ & p-value \\
\hline Intercept & 4.924 & 0.814 & & $<0.001$ \\
\hline Age (years) & -0.018 & 0.026 & -0.052 & 0.491 \\
\hline Sex $($ female $=0$, male $=1)$ & 0.035 & 0.146 & 0.018 & 0.809 \\
\hline HADS-D (year 4) & -0.009 & 0.024 & -0.032 & 0.691 \\
\hline ISI (year 4) & 0.005 & 0.018 & 0.022 & 0.784 \\
\hline MEQ difference (between years 2 and 4 ) & -0.033 & 0.009 & -0.295 & $<0.001$ \\
\hline Splitting at year 2 & -0.237 & 0.084 & -0.220 & 0.005 \\
\hline
\end{tabular}

Dependent variable: Consumption at year $4 . \mathrm{R}^{2}=0.10$, adjusted $\mathrm{R}^{2}=0.07, \mathrm{~F}=3.2(\mathrm{p}<0.05), \mathrm{N}=170$. MEQ: Morningness-Eveningness Questionnaire, HADS-D: Hospital Anxiety and Depression Scale-Depression, ISI: Insomnia Severity Scale 
Table 6. Multiple linear regression assessing changes in defense mechanisms and chronotype differences during clerkship as predictors of use of the immature defense style at year 4

\begin{tabular}{lccrc} 
& B & Standard error & $\beta$ & \multicolumn{2}{c}{ p-value } \\
Intercept & 3.261 & 0.424 & -0.044 & 0.525 \\
Age (years) & -0.009 & 0.015 & -0.031 & 0.664 \\
Sex (female=0, male=1) & -0.036 & 0.082 & 0.087 & 0.244 \\
HADS-D (year 4) & 0.016 & 0.013 & 0.135 & 0.072 \\
ISI (year 4) & 0.019 & 0.010 & -0.254 & 0.001 \\
MEQ difference (between years 2 and 4) & -0.017 & 0.005 & 0.397 \\
Splitting difference (between years 2 and 4) & 0.221 & 0.040 & $<0.001$ \\
\hline
\end{tabular}

Dependent variable: Immature defense style at year $4 . \mathrm{R}^{2}=0.24$, adjusted $\mathrm{R}^{2}=0.21, \mathrm{~F}=8.3(\mathrm{p}<0.001), \mathrm{N}=169$. MEQ: Morningness-Eveningness Questionnaire, HADS-D: Hospital Anxiety and Depression Scale-Depression, ISI: Insomnia Severity Scale

Table 7. Multiple linear regression assessing defense mechanisms after clerkship as a predictor of morningness/eveningness at year 4 after controlling for sleep habit-related variables

\begin{tabular}{|c|c|c|c|c|}
\hline & B & Standard error & $\beta$ & p-value \\
\hline Intercept & 45.120 & 7.810 & & $<0.001$ \\
\hline Age (years) & 0.147 & 0.243 & 0.047 & 0.545 \\
\hline Sex $($ female $=0$, male $=1)$ & -4.470 & 1.319 & -0.252 & 0.001 \\
\hline Year-group & 3.132 & 1.022 & 0.236 & 0.003 \\
\hline HADS-D (year 4) & 0.355 & 0.212 & 0.134 & 0.095 \\
\hline ISI (year 4) & -0.444 & 0.164 & -0.214 & 0.008 \\
\hline Rising time misalignment between weekdays and weekends (year 4) & -0.395 & 0.867 & -0.054 & 0.649 \\
\hline Weekend oversleep (year 4) & -1.130 & 0.814 & -0.166 & 0.168 \\
\hline Exposure duration (h) to sunlight between 10:00 and 15:00 & 1.616 & 1.053 & 0.118 & 0.127 \\
\hline Sublimation (year 4) & 1.707 & 0.687 & 0.189 & 0.014 \\
\hline Consumption (year 4) & -0.731 & 0.717 & -0.078 & 0.310 \\
\hline Passive aggression (year 4) & -1.798 & 0.718 & -0.198 & 0.014 \\
\hline
\end{tabular}

Dependent variable: Morningness in year 4 as measured by the MEQ. $\mathrm{R}^{2}=0.35$, adjusted $\mathrm{R}^{2}=0.29, \mathrm{~F}=6.1(\mathrm{p}<0.001), \mathrm{N}=136 . \mathrm{MEQ}$ : MorningnessEveningness Questionnaire, HADS-D: Hospital Anxiety and Depression Scale-Depression, ISI: Insomnia Severity Scale

ing. Morningness may be socially desirable; morning types manage time cues and arousal/sleep-wake rhythms better [41,42]. Eveningness may be associated with poor attention to time cues and weak entraining of arousal to a sleep-wake cycle appropriate for clinical schedules $[41,42]$. Therefore, a move toward morningness during clinical clerkship may protect against stressful conditions [43].

Another regression analysis showed that less splitting at year 2, less use of the immature defense style at year 4 , and female sex were significantly associated with a change toward morningness after controlling for age and year-4 depression and sleep quality. Decreased use of an immature defense style was associated with less neuroticism [44] and less depression, as well as a decreased rate of eating and personality disorders $[27,45,46]$. We found that students who moved toward morningness during clinical clerkship tended to employ an immature defense style less frequently. Females have been reported to be more morning-oriented than males during puberty and early adulthood [7,47], and the shift to morningness during puberty occurs earlier in females than in males [47]. However, other studies found no sex differences or even greater eveningness in females [20,48].

In terms of specific defense mechanisms, less splitting at year 2 and less consumption at year 4 were significantly related to a shift toward morningness over time. Interestingly, consumption at year 4 was predicted by a change toward eveningness over time, as was less splitting at year 2. Students who use consumption as a defense may employ alcohol or tobacco to resolve or relieve inappropriate impulses or needs. Eveningness has been associated with substance use and addiction in adults [15-17]. As the circadian preference, circadian gene polymorphisms, and brain reward circuitry may be interrelated, eveningness may directly increase substance abuse [49]. As those who favor eveningness tend to act out and criticize traditional standards [41], a move toward eveningness may increase consumption and substance abuse, especially in those who employ splitting less prior to clinical training. Our previous cross-sectional results from a subpopulation of the present study showed that year-2 eveningness was associated with greater consumption, less sublimation, and male sex [5]. Furthermore, a greater decrease in splitting and a move toward morningness during clinical clerkship were significantly related with less use of the immature defense style at year 4 in this study. Splitting is a typical image-distorting defense [27] used primarily by those with borderline personality disorder [50,51]. Students who gradually abandon splitting as clinical learning proceeds may increasingly integrate their self-image with other images, directly reducing use of the immature defense. Moreover, students who attain increasingly 
better control of the sleep-wake cycle, which then becomes compatible with their social schedules, may gradually forsake use of the immature defense style.

Morningness at year 4 was associated with greater sublimation, less passive aggression, better sleep quality, female sex, and yeargroup (i.e., group I, II, and III) after controlling for depression; it was also associated with rise time misalignment between weekdays and weekends, weekend oversleeping, and mean sunlight exposure between 10:00 and 15:00. Sublimation is a sophisticated way to express instinctual urges that reduces intrapsychic conflict while minimizing any marked loss of pleasure. In sublimation, aggressive impulses are expressed via pleasurable games, sports, or hobbies, and libidinal impulses are expressed in romantic relationships. Unlike neurotic defenses, such as repression, the instincts are channeled rather than dammed or transformed [52,53]. Sublimation is a mature defense style associated with the Big Five personality traits of openness, emotional stability, and extraversion [54]. High levels of openness [8,55] and emotional stability [55] are associated with morningness. Although no relationship between extraversion and morningness has been described [34,36], several studies have found significant associations between lower levels of extraversion and morningness [56,57]. Tankova et al. [34] indicated that morningness and extraversion may be related through impulsivity, which is closely associated with serotonergic functioning $[38,39]$. As sublimation is both an ability and a mental activity controlling diverse internal impulses, an association between greater sublimation and morningness would support a relationship between low impulsivity and morningness. Less use of passive aggression was also associated with morningness in our fourth-year students. Passive aggression is a defense against aggression whereby the latter is expressed indirectly and ineffectively. Individuals who are hostile toward another person exhibit certain behaviors, including procrastination, failure to communicate, and provocation, as expressions of aggression [52]. The DSQ considers passive aggression an immature defense style that is negatively correlated with conscientiousness, agreeableness, and emotional stability [54]. Higher levels of conscientiousness [8,56-58], agreeableness [39,58-60], and emotional stability [55] are associated with morningness. Sublimation and passive aggression are defense mechanisms that seek to deal with instincts that must be self-controlled and self-regulated, both of which are enhanced by morningness [37]. Consistent with previous studies [10,61,62], we found that morningness was associated with better sleep quality. As greater sublimation, lower levels of passive aggression, and better sleep quality may play adaptive roles in terms of enhancing clinical activity, encouraging medical students to develop morning-type sleep-wake cycles may be crucial. We found no significant associations between year- 4 circadian preference and rise time misalignment between weekdays and weekends, weekend oversleeping, or mean daily sunlight exposure in a multiple regression analysis. A future study should explore these topics in a larger population.

Our study had several limitations. First, as chronotype is re- garded as a relatively stable trait in adulthood, the changes in chronotype during the 2-year study period might have occurred by chance. Thus, future prospective studies with larger samples are needed to explore whether there are real changes in chronotype during early adulthood. Second, the influences of environment were not considered in this study. Future studies considering other factors that may have an impact on changes in chronotype are needed. Third, the relationship between consumption/immature defense style and increased morningness may have been bidirectional in nature, but cause-and-effect inferences cannot be drawn.

Despite these limitations, our study has several strengths. First, this is the first study to explore the effects of personality change on chronotype in medical students. To the best of our knowledge, we here describe, for the first time, the relationship between changes in defense mechanisms and styles throughout the course of clinical clerkship with increased morningness. Second, we suggest that natural chronotype modification using social synchronizers might reduce the use of consumption and other immature defense styles.

In conclusion, increased morningness and a gradual reduction in splitting during clinical clerkship may reduce the use of the immature defense style. We suggest that this finding be considered when attempting to reduce medical students' immaturity via changes in chronotype.

\section{Author Contributions}

Conceptualization: Chul-Soo Park, So-Jin Lee, Bong-Jo Kim, Cheol-Soon Lee, Boseok Cha, Jin-Seong Lee. Data curation: Chul-Soo Park, So-Jin Lee, Dongyun Lee, Jiyeong Seo, Jae-Won Choi. Formal analysis: Chul-Soo Park, So-Jin Lee, Cheol-Soon Lee, and Dongyun Lee. Investigation: Chul-Soo Park, So-Jin Lee, BongJo Kim, Cheol-Soon Lee, Boseok Cha, Jin-Seong Lee. Methodology: Chul-Soo Park, So-Jin Lee, Bong-Jo Kim, Cheol-Soon Lee, Boseok Cha, Jin-Seong Lee. Project administration: Chul-Soo Park, So-Jin Lee, Bong-Jo Kim, Boseok Cha. Resources: Chul-Soo Park, Bong-Jo Kim, Cheol-Soon Lee, Boseok Cha. Software: ChulSoo Park, So-Jin Lee. Supervision: Chul-Soo Park, Boseok Cha, Jin-Seong Lee. Validation: Bong-Jo Kim, Cheol-Soon Lee, Dongyun Lee, Jiyeong Seo, Jae-Won Choi. Visualization: Dongyun Lee, Jiyeong Seo, Jae-Won Choi. Writing-original draft: Chul-Soo Park, So-Jin Lee, Boseok Cha. Writing-review \& editing: Chul-Soo Park, So-Jin Lee, Bong-Jo Kim, Cheol-Soon Lee, Boseok Cha, Jin-Seong Lee, Dongyun Lee, Jiyeong Seo, Jae-Won Choi.

\section{ORCID iDs}

Chul-Soo Park (1)

https://orcid.org/0000-0003-0530-7960

So-Jin Lee (10)

https://orcid.org/0000-0003-2904-9206

\section{REFERENCES}

1. Azad MC, Fraser K, Rumana N, Abdullah AF, Shahana N, Hanly P, et al. Sleep disturbances among medical students: a global perspective. J Clin Sleep Med 2015;11:69-74. 
2. Zailinawati AH, Teng CL, Chung YC, Teow TL, Lee PN, Jagmohni KS. Daytime sleepiness and sleep quality among Malaysian medical students. Med J Malaysia 2009;64:108-110.

3. Huen L-LE, Chan T-WG, Yu W-MM, Wing Y-K. Do medical students in Hong Kong have enough sleep? Sleep Biol Rhythms 2007;5:226-230.

4. Hsu CY, Gau SS, Shang CY, Chiu YN, Lee MB. Chronobiol Int 2012;29: 491-501.

5. Lee SJ, Park CS, Kim BJ, Lee CS, Cha BS, Kang H. Circadian preference and defense in medical students: greater consumption and lesser sublimation predicting eveningness. Sleep Med Psychophysiol 2013;20:82-87.

6. Tsaousis I. Circadian preferences and personality traits: a meta-analysis. Eur J Pers 2010;24:356-373.

7. Adan A, Archer SN, Hidalgo MP, Di Milia L, Natale V, Randler C. Circadian typology: a comprehensive review. Chronobiol Int 2012;29:1153-1175.

8. Duggan KA, Friedman HS, McDevitt EA, Mednick SC. Personality and healthy sleep: the importance of conscientiousness and neuroticism. PLoS One 2014;9:e90628.

9. Adan A, Almirall H. The influence of age, work schedule and personality on morningness dimension. Int J Psychophysiol 1992;12:95-99.

10. Kitamura S, Hida A, Watanabe M, Enomoto M, Aritake-Okada S, Moriguchi $\mathrm{Y}$, et al. Evening preference is related to the incidence of depressive states independent of sleep-wake conditions. Chronobiol Int 2010;27:1797-1812.

11. Bielen J, Melada A, Markelić I. Depression and circadian typology. Psychiatr Danub 2015;27:190-192.

12. Merikanto I, Lahti T, Kronholm E, Peltonen M, Laatikainen T, Vartiainen E, et al. Evening types are prone to depression. Chronobiol Int 2013;30:719-725.

13. Bromundt V, Wirz-Justice A, Kyburz S, Opwis K, Dammann G, Cajochen C. Circadian sleep-wake cycles, well-being, and light therapy in borderline personality disorder. J Pers Disord 2013;27:680-696.

14. Sottile PD, Lynch Y, Mealer M, Moss M. Association between resilience and family member psychologic symptoms in critical illness. Crit Care Med 2016; 44:e721-e727.

15. Wittmann M, Dinich J, Merrow M, Roenneberg T. Social jetlag: misalignment of biological and social time. Chronobiol Int 2006;23:497-509.

16. Broms U, Kaprio J, Hublin C, Partinen M, Madden PA, Koskenvuo M. Evening types are more often current smokers and nicotine-dependent-a study of Finnish adult twins. Addiction 2011;106:170-177.

17. Tavernier R, Willoughby T. Are all evening-types doomed? Latent class analyses of perceived morningness-eveningness, sleep and psychosocial functioning among emerging adults. Chronobiol Int 2014;31:232-242.

18. Lemoine P, Zawieja P, Ohayon MM. Associations between morningness/eveningness and psychopathology: an epidemiological survey in three in-patient psychiatric clinics. J Psychiatr Res 2013;47:1095-1098.

19. Gelbmann G, Kuhn-Natriashvili S, Pazhedath TJ, Ardeljan M, Wöber C, Wöber-Bingöl C. Morningness: protective factor for sleep-related and emotional problems in childhood and adolescence? Chronobiol Int 2012;29:898910.

20. Zimmermann LK. Chronotype and the transition to college life. Chronobiol Int 2011;28:904-910.

21. Roenneberg T, Kuehnle T, Pramstaller PP, Ricken J, Havel M, Guth A, et al. A marker for the end of adolescence. Curr Biol 2004;14:R1038-R1039.

22. Lee SJ. The relationship of defense changes during clinical clerkship with physician-patient interactions, resilience, and circadian preference (unpublished doctoral dissertation). Jinju: Gyeongsang National University; 2018.

23. Cho S. A validation study of Korean version of Defense Style Questionnaire. Korean J Couns Psychotherapy 1999;11:115-137.

24. Horne JA, Ostberg O. A self-assessment questionnaire to determine morningness-eveningness in human circadian rhythms. Int J Chronobiol 1976;4: 97-110.

25. Zigmond AS, Snaith RP. The hospital anxiety and depression scale. Acta Psychiatr Scand 1983;67:361-370.

26. Cho YW, Song ML, Morin CM. Validation of a Korean version of the insomnia severity index. J Clin Neurol 2014;10:210-215.

27. Bond M. Empirical studies of defense style: relationships with psychopathology and change. Harv Rev Psychiatry 2004;12:263-278.

28. Bjelland I, Dahl AA, Haug TT, Neckelmann D. The validity of the hospital anxiety and depression scale. An updated literature review. J Psychosom Res 2002;52:69-77.

29. Andrews B, Hejdenberg J, Wilding J. Student anxiety and depression: com- parison of questionnaire and interview assessments. J Affect Disord 2006; 95:29-34.

30. Oh SM, Min KJ, Park DB. A Study on the standardization of the hospital anxiety and depression scale for Koreans: a comparison of normal, depressed and anxious groups. J Korean Neuropsychiatr Assoc 1999;38:289-296.

31. Lee JH, Kim SJ, Lee SY, Jang KH, Kim IS, Duffy JF. Reliability and validity of the Korean version of Morningness-Eveningness Questionnaire in adults aged 20-39 years. Chronobiol Int 2014;31:479-486.

32. Yu N, Shin S, Wang S. A study on the standardization of the Korean version of J.A Horne and O.Ostbergs' Morningness-Eveningness Questionnaire and on the sleep pattern. J Korean Neuropsychiatr Assoc 1995;34:642-656.

33. Randler C. Proactive people are morning people. J Appl Soc Psychol 2009;39: 2787-2797.

34. Tankova I, Adan A, Buela-Casal G. Circadian typology and individual differences. A review. Pers Individ Dif 1994;16:671-684.

35. Vollmer C, Randler C. Circadian preferences and personality values: morning types prefer social values, evening types prefer individual values. Pers Individ Dif 2012;52:738-743.

36. Mecacci L, Rocchetti G. Morning and evening types: stress-related personality aspects. Pers Individ Dif 1998;25:537-542.

37. Digdon NL, Howell AJ. College students who have an eveningness preference report lower self-control and greater procrastination. Chronobiol Int 2008;25: 1029-1046.

38. Caci H, Mattei V, Baylé FJ, Nadalet L, Dossios C, Robert P, et al. Impulsivity but not venturesomeness is related to morningness. Psychiatry Res 2005;134: 259-265.

39. DeYoung CG, Hasher L, Djikic M, Criger B, Peterson JB. Morning people are stable people: circadian rhythm and the higher-order factors of the Big Five. Pers Individ Dif 2007;43:267-276.

40. Soubrie P. Reconciling the role of central serotonin neurons in human and animal behavior. Behav Brain Sci 1986;9:319-335.

41. Díaz-Morales JF. Morning and evening-types: exxploring their personality styles. Pers Individ Dif 2007;43:769-778.

42. Korczak AL, Martynhak BJ, Pedrazzoli M, Brito AF, Louzada FM. Influence of chronotype and social zeitgebers on sleep/wake patterns. Braz J Med Biol Res 2008;41:914-919.

43. Lee SJ, Park CS, Kim BJ, Lee CS, Cha B, Lee YJ, et al. Association between morningness and resilience in Korean college students. Chronobiol Int 2016; 33:1391-1399.

44. Muris P, Merckelbach H. The short version of the Defense Style Questionnaire: factor structure and psychopathological correlates. Pers Individ Dif 1996;20:123-126

45. Spinhoven P, Kooiman CG. Defense style in depressed and anxious psychiatric outpatients: an explorative study. J Nerv Ment Dis 1997;185:87-94.

46. Hyphantis T. The Greek version of the Defense Style Questionnaire: psychometric properties in three different samples. Compr Psychiatry 2010;51:618629.

47. Randler C, Faßl C, Kalb N. From Lark to Owl: developmental changes in morningness-eveningness from new-borns to early adulthood. Sci Rep 2017; 7:45874.

48. Paine SJ, Gander PH, Travier N. The epidemiology of morningness/eveningness: influence of age, gender, ethnicity, and socioeconomic factors in adults (30-49 years). J Biol Rhythms 2006;21:68-76.

49. Logan RW, Williams WP 3rd, McClung CA. Circadian rhythms and addiction: mechanistic insights and future directions. Behav Neurosci 2014;128: $387-412$.

50. Mun BY, Jeong JY, Lee HR, Song SH, Lee JY, Koo BH. Gender difference in clinical and psychological characteristics in patients with borderline personality disorder at a university hospital. Psychoanalysis 2011;22:9-18.

51. Zanarini MC, Weingeroff JL, Frankenburg FR. Defense mechanisms associated with borderline personality disorder. J Pers Disord 2009;23:113-121.

52. Vaillant GE. Ego mechanisms of defense: a guide for clinicans and researchers. Washington, DC: American Psychiatric Press; 1992.

53. Fenichel O. The psychoanalytic theory of neurosis. New York, NY: W W Norton \& Co.; 1995.

54. Soldz S, Budman S, Demby A, Merry J. The relation of defensive style to personality pathology and the big five personality factors. J Pers Disord 1995;9: 356-370.

55. Cavallera GM, Gatto M, Boari G. Personality, cognitive styles and Morn- 
ingness-Eveningness disposition in a sample of Yoga trainees. Med Sci Monit 2014;20:238-246.

56. Langford C, Glendon AI. Effects of neuroticism, extraversion, circadian type and age on reported driver stress. Work Stress 2002;16:316-334.

57. Mitchell PJ, Redman JR. The relationship between morningness-eveningness, personality and habitual caffeine consumption. Pers Individ Dif 1993;15: 105-108.

58. Hogben AL, Ellis J, Archer SN, von Schantz M. Conscientiousness is a predictor of diurnal preference. Chronobiol Int 2007;24:1249-1254.
59. Qu W, Ge Y, Xiong Y, Carciofo R, Zhao W, Zhang K. Dangerous driving in a Chinese sample: associations with morningness-eveningness preference and personality. PLoS One 2015;10:e116717.

60. Randler C. Morningness-eveningness, sleep-wake variables and big five personality factors. Pers Individ Dif 2008;45:191-196.

61. Carrier J, Monk TH, Buysse DJ, Kupfer DJ. Sleep and morningness-eveningness in the 'middle' years of life (20-59 y). J Sleep Res 1997;6:230-237.

62. Giannotti F, Cortesi F, Sebastiani T, Ottaviano S. Circadian preference, sleep and daytime behaviour in adolescence. J Sleep Res 2002;11:191-199. 